\title{
EVALUATION OF COSMETIC PROPERTIES OF NATURAL INGREDIENTS IN THE TRÁS-OS-MONTES AREA: A PHD PROJECT
}

Sara Gonçalves and Isabel Gaivão

Department of Genetics and Biotechnology and CECAV, University of Trás-os-Montes and Alto Douro, Quinta de Prados, 5000 Vila Real, Portugal

\section{What do we know?}

Danish Council

\section{THINK}

\section{Chemicals}

Found 65 chemicals in 39 products and 3 products

contained illegal ingredients in the EU

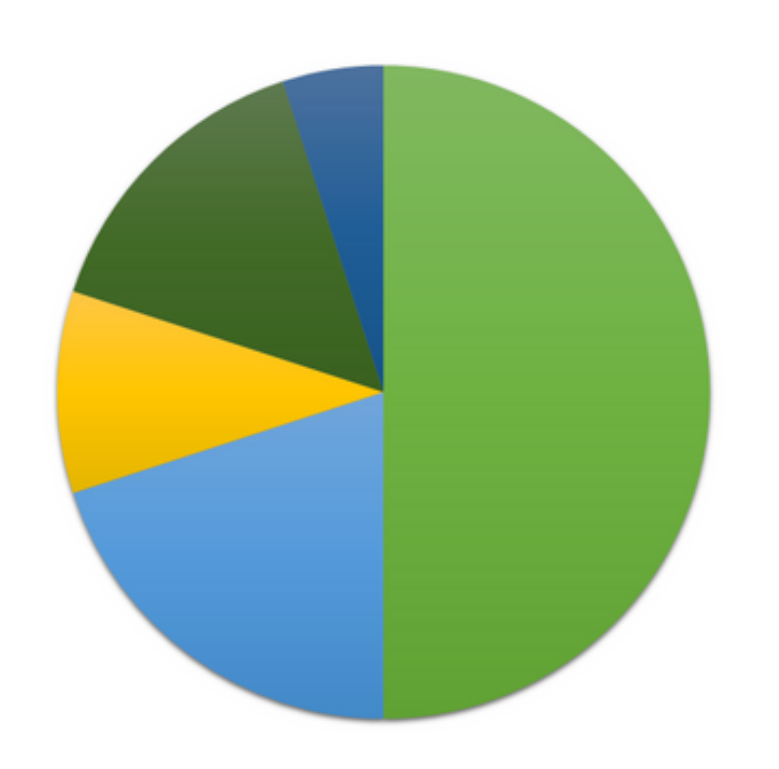

About $50 \%$ of French consumers decided to buy organic cosmetics after realizing the ecological impact of non-organic products

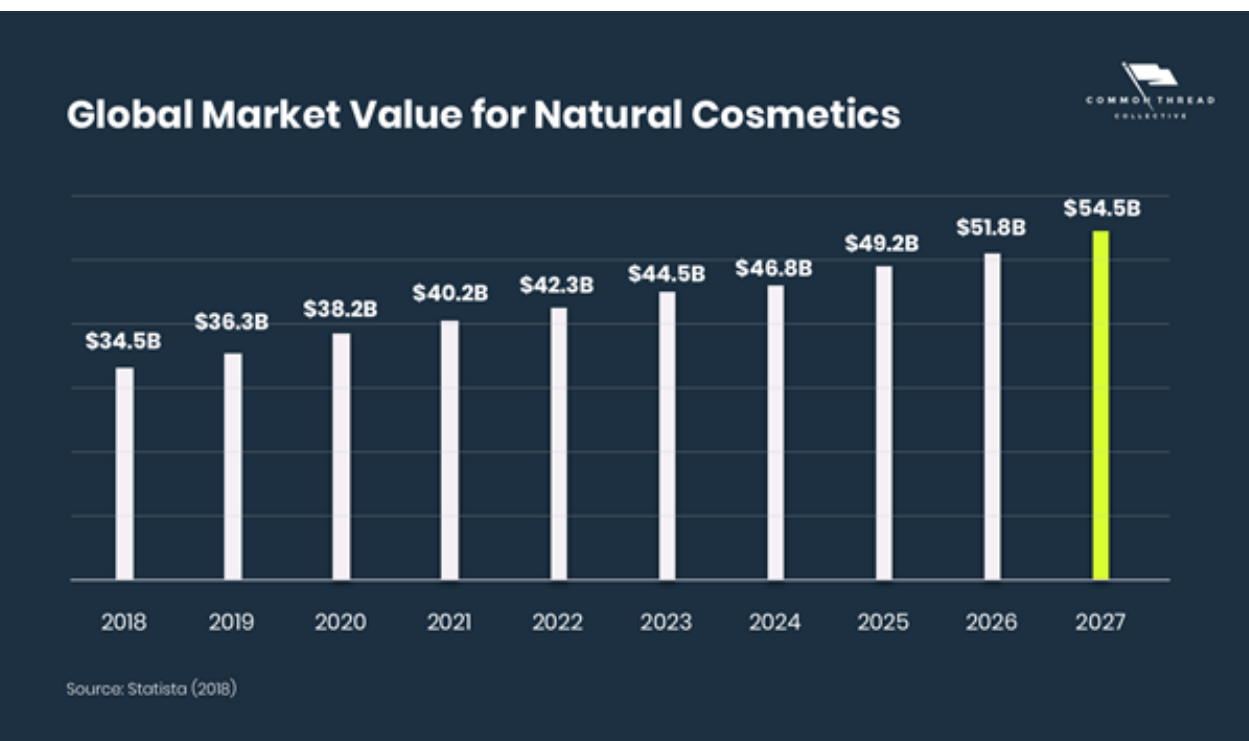

Analysts anticipate a global revenue of US $\$ 54,432.2 \mathrm{Mn}$ by 2027 , at an annual growth of $5.2 \%$ during this period.

\section{What can we do?}

1
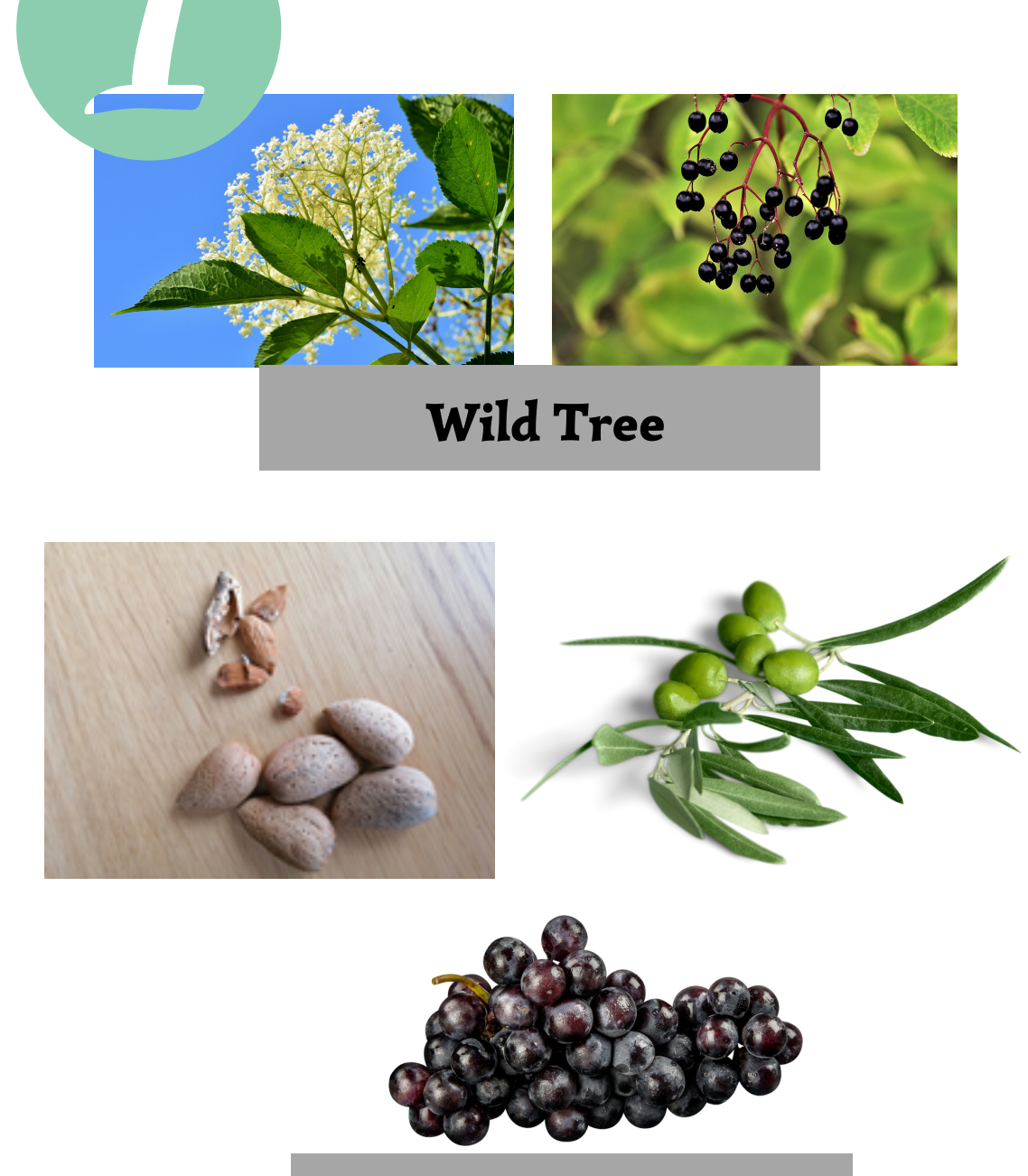

Organic farming

Harvest and preparation

Elderberry flower and berries, almonds, olives and grapes

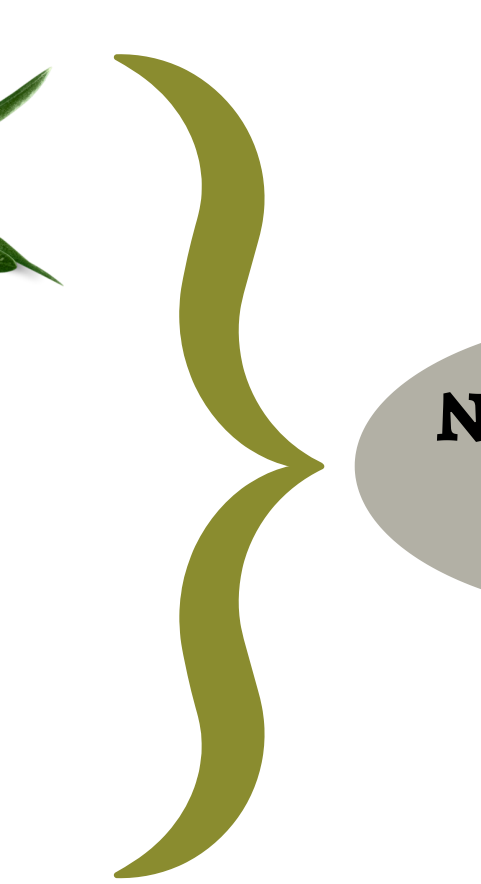
agriculture

The use of natural and organic cosmetics becomes increasingly important. This requires a strong investigation into the benefits that fruits and plants can bring to our health.

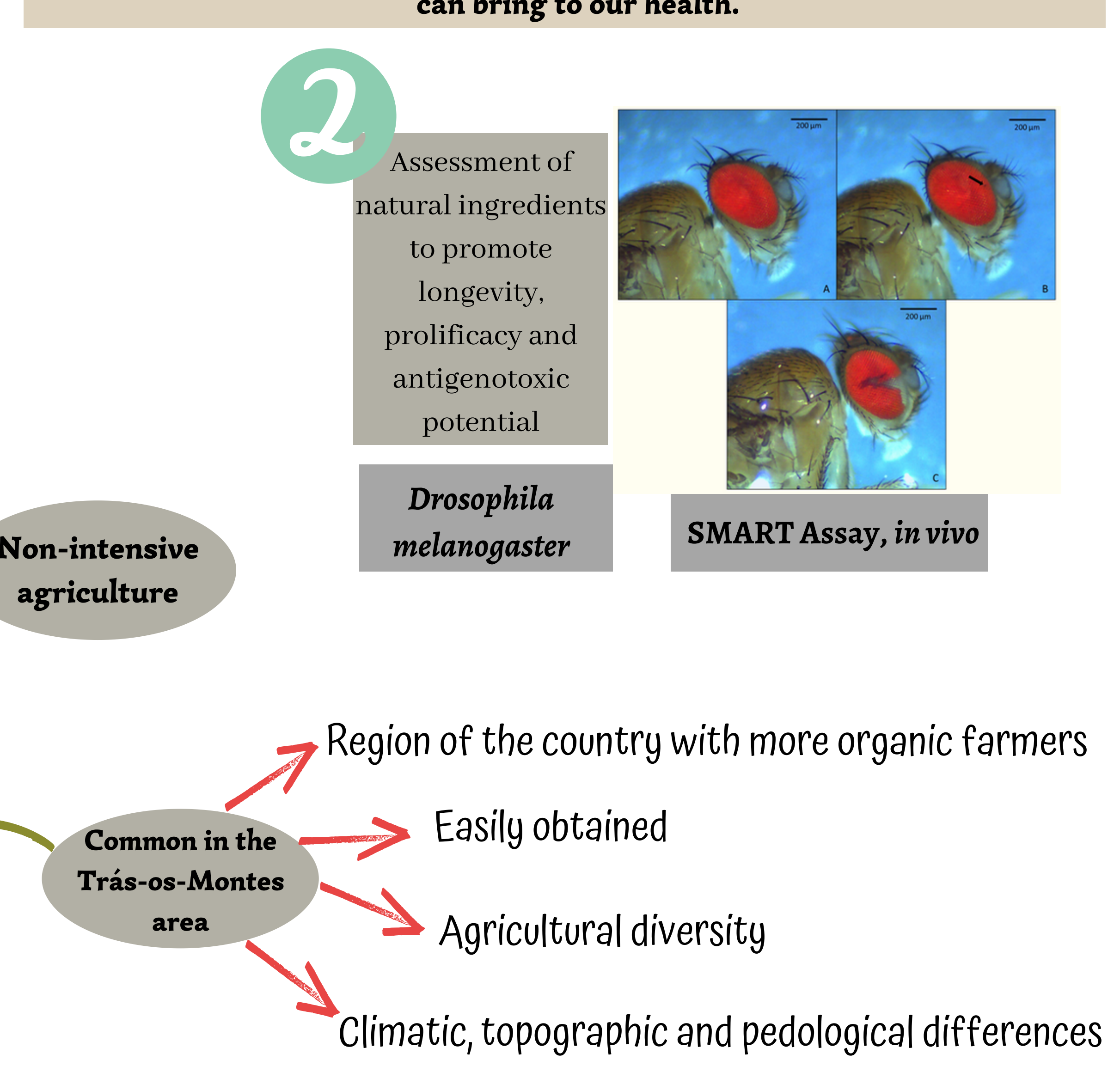

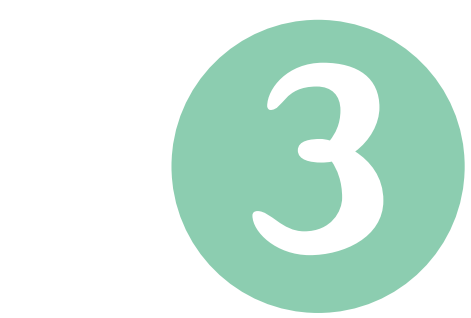

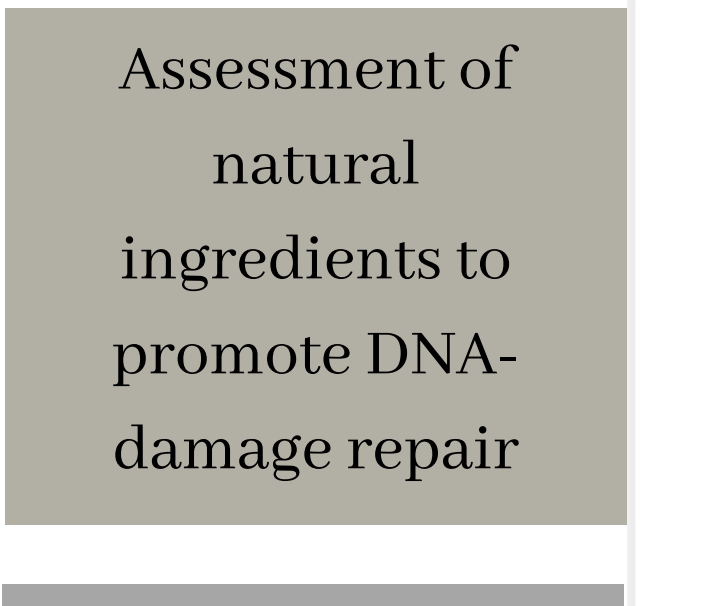

Comercial Cell Line

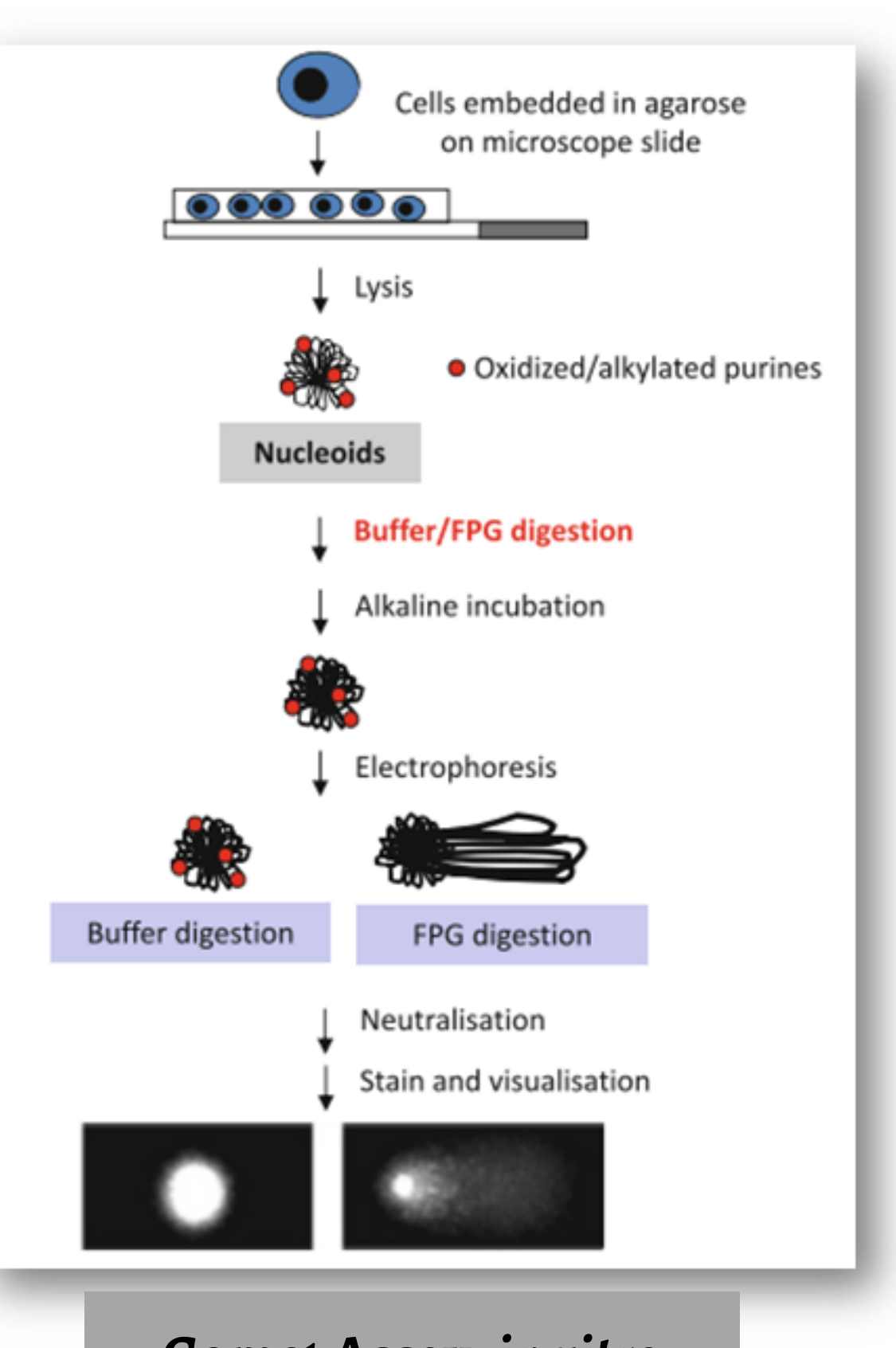

Comet Assay, in vitro

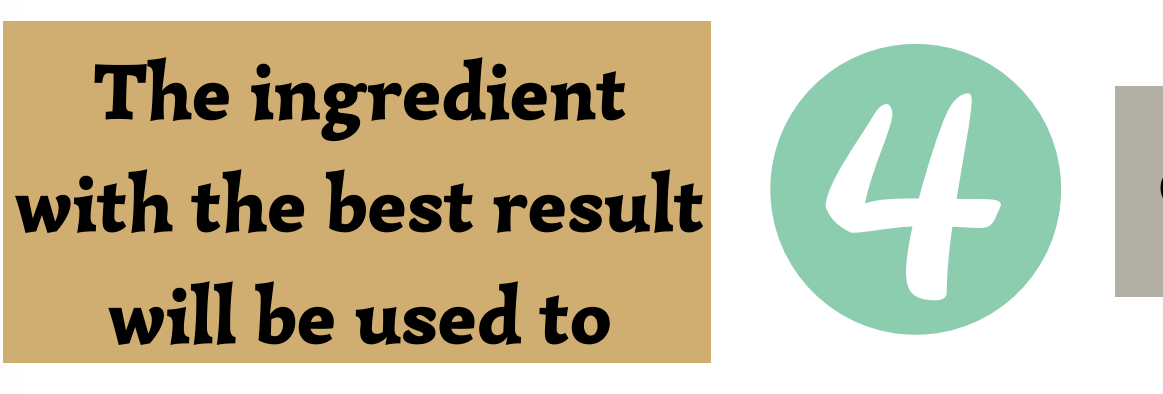

will be used to

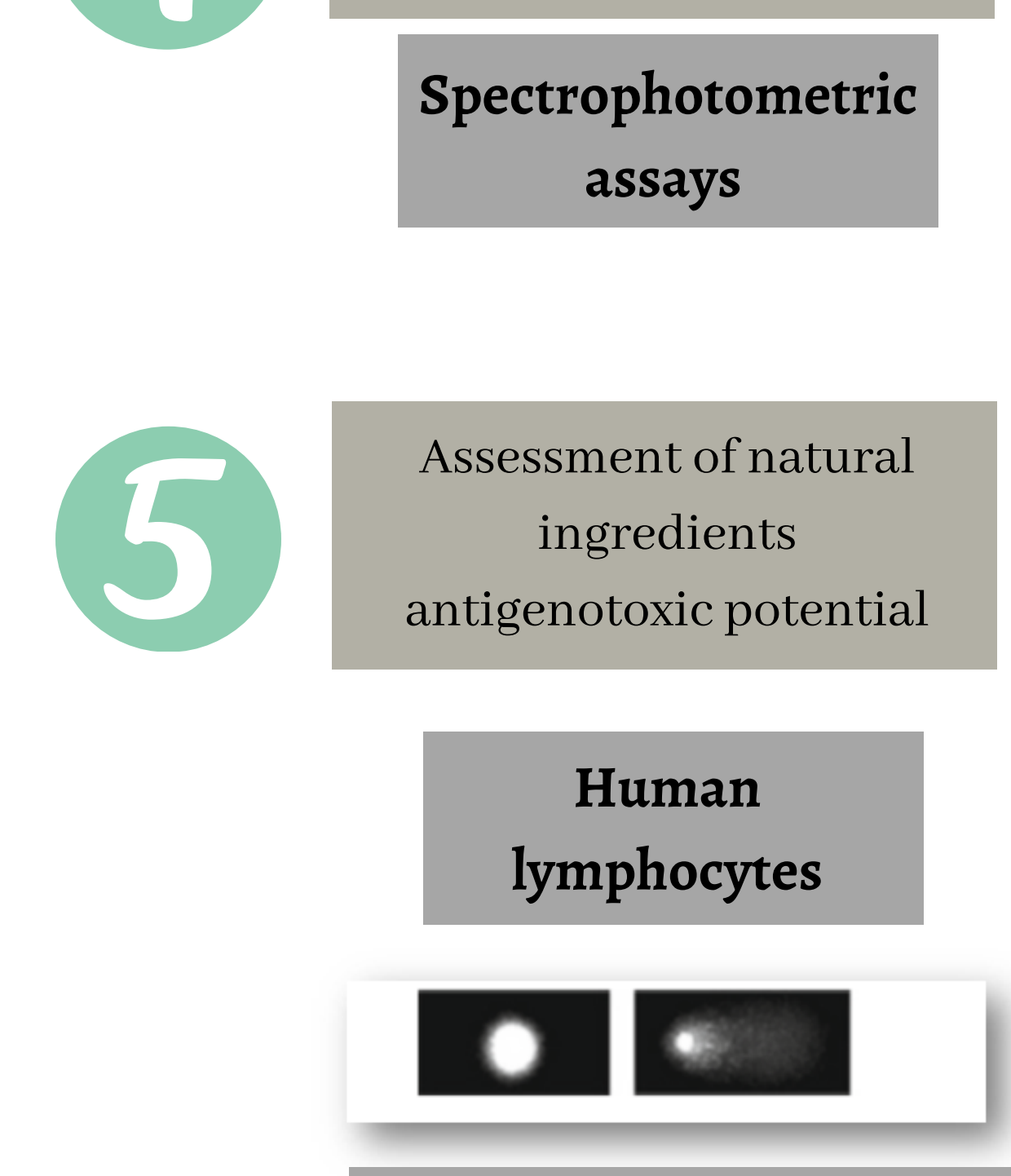

Comet Assay, in vivo

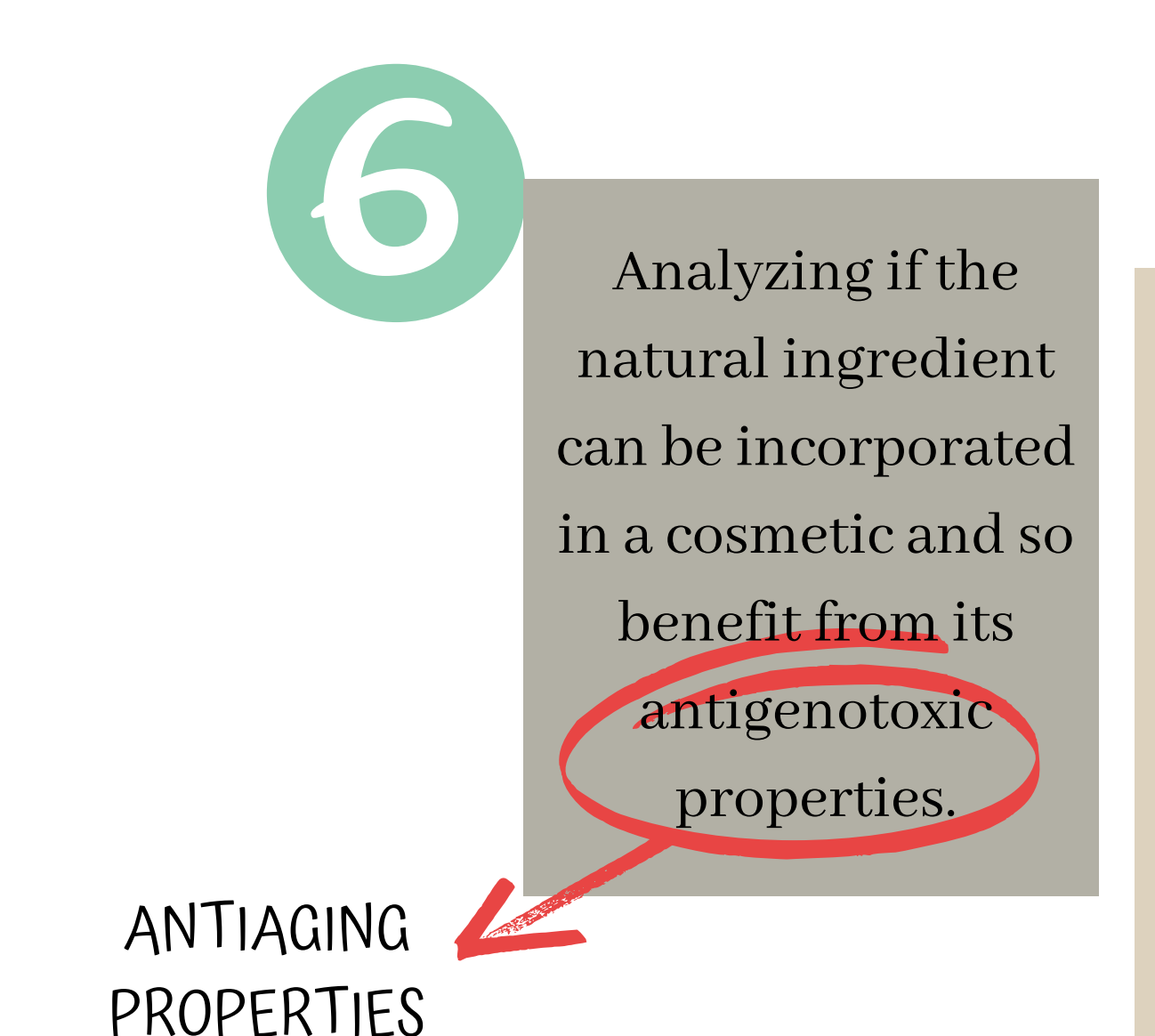

Aknowledgment

This research will be financed by

FCT to CECAV

(UIDB/CVT/00772/2020)

\section{$\underline{\text { References }}$}

1) Jørgensen C. Cosmetics worldwide - same contents? A comparative study. Dinamarca: The Danish Consumer Council THINK Chemicals; 2020.

Natural cosmetics: sales value France. Statista 2015. https://www.statista.com/statistics/671090/natural-organic-cosmetics-sales-value-france/ (accessed November 2, 2020).

2) Natural and organic cosmetics: share of female users France 2016. Statista 2016. https://www.statista.com/statistics/671247/natural-organic-cosmetics-share-women-france/ (accessed November 2, 2020).

3) Organic cosmetics: decisive moments for consumption France 2016. Statista 2016. https:/www.statista.com/statistics/671320/key-moments-consumer-organic-cosmetics-france/ (accessed November 2, 2020).

4) Sierra LM, Gaivão I, editors. Genotoxicity and DNA Repair. New York, NY: Springer New York; 2014. https://doi.org/10.1007/978-1-4939-1068-7.

5) Gaivão I, Ferreira J, María Sierra L. The w / w + Somatic Mutation and Recombination Test (SMART) of Drosophila melanogaster for Detecting Antigenotoxic Activity. Antimutagens Mech. DNA Prot. Work. Title, IntechOpen; 2020. https://doi.org/10.5772/intechopen.91630. 